A better outcome for infantile spasms: What is the evidence? Sri Lanka Journal of Child Health, 2015; 44(3): 129137

Professor C. C. de Silva Oration-2014

\title{
A better outcome for infantile spasms: What is the evidence?
}

\author{
*Jithangi Wanigasinghe ${ }^{1}$ \\ Sri Lanka Journal of Child Health, 2015; 44(3): 129-137
}

(Key words: Infantile spasms; outcome)

It is indeed a privilege to stand before you today and speak in honour of one of the great paediatricians produced by this country. Professor Cholomondley Chalmers de Silva, known to his friends as Chummy, became the first Professor of Paediatrics when he joined the then University of Ceylon in 1949. With this he became a Visiting Paediatrician to the Lady Ridgeway Hospital (LRH) as well. As an academic, researcher and an administrator, he has rendered a great service to this country. As an academic, he worked hard to improve the standard of paediatric undergraduate and postgraduate education. Establishment of the Diploma in Child Health (DCH) was one of his major accomplishments. He was one of the best researchers in his era and made the University Unit at LRH a centre for research. His main interests included nutritional disorders, haemoglobinopathies and infective diarrhoeas. He was instrumental in the establishment of the Convalescent Home for nutritional rehabilitation of malnourished children at Thalagolla. As a member of the department which he headed, it is my greatest privilege to speak to you tonight on research which we have conducted in the same unit he established many years ago. In honour of this great paediatrician, I will now speak to you about "A better outcome for infantile spasms: What is the evidence?"

Infantile spasms (IS) are a unique epilepsy syndrome that causes devastating effects on the developing brain. It is rare, affecting 3 to 5 per 10,000 live births. It was Dr. William James West who described this condition for the first time in his own infant son in $1841^{1}$. Spasms are seizures manifesting as brief contractions of any group of muscles, flexors, extensors or a mix of the two. They occur in clusters which are often associated with crying. Classically, they occur during the first year of life, peaking between 4-6 months and hence the initial terminology 'infantile spasms'. It is known to follow an insult which precedes the onset by several months. Onset

\footnotetext{
${ }^{1}$ Senior Lecturer and Honorary Paediatric Neurologist, University of Colombo, Sri Lanka

*Correspondence: jithangi@gmail.com
}

after one year is considered as "late onset epileptic spasms", which rarely may occur even as late as four years of life. In our series of patients we had four rare cases of spasms that followed insults which occurred beyond 24 months of life 2 .

The spasms are associated with a grossly abnormal electroencephalographic (EEG) pattern, known as hypsarrhythmia. This consists of multifocal epileptic activity as high amplitude spikes occurring in a grossly altered background consisting of irregular slow waves of high amplitude, leading to a chaotic mixture of arrhythmic and asynchronous brain activity. This hypsarrhythmic EEG pattern is known to change with time within the same patient, from its first appearance. The typical hypsarrhythmia is seen during infancy, after which the discharges tend to become synchronised.

Developmental arrest or regression is the most devastating component of the triad of the West Syndrome. Although considered to occur concomitantly, research has shown this regression to precede the onset of spasms. Philippi et al in 2008 demonstrated three distinct clinical stages accompanied by three different evolving EEG patterns ${ }^{3}$. Clinical stage one (few weeks to months), known as the silent phase, presents with multifocal epileptic discharges of over $50 \%$ in the non-rapid eye movement (NREM) sleep record. Clinical stage 2, which may last for several weeks, shows the beginning of the deterioration in development. The accompanying EEG shows increased bi-hemispheric epileptic discharges occurring in more than $50 \%$ of the recording time within abnormal background activity. Clinical stage 3 is associated with a definite deterioration of development manifesting as loss of gross motor abilities, loss of hand functions, auditory agnosia and cortical blindness. The EEG in this stage is associated with classical hypsarrhythmia. All these three clinical and EEG stages precede the occurrence of spasms. 
A better outcome for infantile spasms: What is the evidence? Sri Lanka Journal of Child Health, 2015; 44(3): 129137

\section{Pathogenesis of spasm generation}

Although many different mechanisms are postulated we have not yet clearly understood how the spasms are generated. This is in spite of major advances such as intracranial electroencephalography, functional neuroimaging, and even the development of an epileptic spasm mouse model. There are many questions that remain unanswered. In the absence of a clear understanding on the pathogenesis, treatment of this condition has been largely empirical. The word empirical is defined as strategic but scientifically unproven. One way to overcome this gap in knowledge is rigorous analysis of the evidence for empirical standard treatments. Outcome of such rigorous analysis is hindered by several factors. There is a great paucity of prospective studies on treatment of IS $^{4,5}$. Well conducted randomised clinical trials are just a handful. Up to the 2013 Cochrane review, there were only 18 clinical trials (16 small and 2 large $)^{4}$. Most treatment trials are under-powered due to small sample sizes. Another major limitation is that the dosage regimens and treatment durations vary widely from study to study. Continental preferences are another issue: Different regimes are promoted in different continents and settings. What is promoted in the European Union is different to that in the United States or the one in $\operatorname{Japan}^{6}$. Critical evaluation of the current literature reveals that the so called "empirical evidence" is limited to "available evidence" emanating from studies with small sample sizes, preferential doses of medications, and limited to studies from centres of favoured choices.

\section{Adrenocorticotropic hormone and steroids}

Adrenocorticotropic hormone (ACTH) secreted from the pituitary gland has been used for treatment of IS since $1958^{7}$. The long acting form, administered intramuscularly is used for this treatment. Available research on ACTH is less than 20 papers. This includes randomized clinical trials, open label studies and even retrospective case series. Different formulations of ACTH (natural versus synthetic) have been used in these studies. Dosages of ACTH were markedly variable from $0.2 \mathrm{IU} / \mathrm{kg}$ up to $150 \mathrm{IU} /$ square metre. The duration of treatment as well as the reported outcomes (42 to $87 \%$ response rate) vary widely ${ }^{4}$. The other important concern pertaining to ACTH treatment is the enormous cost of therapy. In the United States the cost of a vial exceeds 70,000 US dollars ${ }^{8}$. Recent further increase in price has made this therapy not affordable even across the Atlantic. In Sri Lanka, a vial of synthetic ACTH costs between 9,000 to 10,000 rupees.

\section{Vigabatrin}

Vigabatrin (VGB) which acts by inhibiting gamma amino butyric acid (GABA) transaminase irreversibly has been used for treatment of spasms since 1990. It remained the favoured therapy particularly in the countries of the European Union (EU) till recent years. In Europe, VGB was recommended as the drug of first choice for children with IS secondary to tuberous sclerosis (TSC) as well as other forms of symptomatic and cryptogenic IS ${ }^{9}$. This preference for VGB was supported by the high response rate reported in a cohort of children with TSC by Chiron et $\mathrm{al}^{10}$ and a randomised placebo controlled trial by Appelton et $\mathrm{al}^{11}$. The main drawbacks related to VGB are the permanent peripheral visual field loss and the white matter changes in subcortical regions ${ }^{4}$. It is also enormously costly, averaging 12,000 to 15,000 Sri Lankan rupees for a supply of medications for a month. It is also not available or registered in many countries.

\section{Prednisolone and other steroids}

Prednisolone and prednisone are other forms of hormonal therapy that have been used for IS for over 40 years. However, due to the absence of sufficient evidence, they have not been recognised as first-line therapy for IS ${ }^{4,5,12}$. Case series, personal experience and open label studies have been inadequate to challenge the superior response rate established by trials such as that of Tali Baram's group using high dose of ACTH (150iu/square metre) against a low dose of $2 \mathrm{mg} / \mathrm{kg} /$ day of prednisone ${ }^{13}$. The best up to now has been equivalent responses shown for low dose ACTH and $2 \mathrm{mg} / \mathrm{kg}$ prednisone by Hrachovy and Lombroso et al in $1983^{14}$. Similar outcome was shown in the United Kingdom Infantile Spams Study (UKISS) trial which compared the outcome of highdose oral prednisolone (40-60mg/day) with low dose intramuscular ACTH, spasms responder rates at end of 14 days being $76 \%$ for synthetic ACTH and $70 \%$ for prednisolone $^{15}$. Neither agent showed a significant difference in the EEG response rate at 14 days $(p=0.61)$. Similar findings of equal response rate were seen at 14 month follow up ${ }^{16}$. Unfortunately, due to inadequate power in the findings, this was insufficient evidence to support prednisolone as being equal to ACTH for treatment of IS. Prednisolone is a tablet, easily dispensable from home and is very cheap. It costs less than 75 Sri Lankan rupees to complete 14 days of therapy and such low pricing is the same worldwide. 


\section{Research on IS in Sri Lanka}

My personal interest in IS runs back to early 2003. Serial patients treated with intramuscular ACTH $40 \mathrm{IU}$ on a daily basis were followed up. There were 20 patients including 13 with IS. Others were classified as other syndromic epilepsies (myoclonic epilepsy, Lennox-Gastaut syndrome and Dravet syndrome). We documented $85 \%$ spasm freedom at 2 weeks and $15 \%$ spasm freedom at 12 months. In the symptomatic group, only one patient became seizure free with $\mathrm{ACTH}^{17}$.

Since the publication of UKISS trial, I was keen to assess the response rate to this protocol in our patients. This was documented in a group of 30 infants treated using the UKISS protocol [oral prednisolone (40-60 $\mathrm{mg}$ /day) or intramuscular ACTH (40-60 IU every other day) for 14 days or Vigabatrin 100$150 \mathrm{mg} / \mathrm{kg} /$ day for patients with tuberous sclerosis). With this $66 \%$ were spasm free at 14 days and $93 \%$ showed improvement on the post treatment $\mathrm{EEG}^{18}$. This spasm freedom was comparable to that described in the UKISS study.

It was also important to document the adverse events profile of high dose hormonal therapies, particularly when used in the local setting with high turnover rates and problems mostly related to infection. The adverse event profile was documented in 35 children who were treated with the UKISS protocol. Contrary to expectation, the detected rate of sepsis was minimal. These findings confirmed the feasibility of using this UKISS regime in settings like Sri Lanka ${ }^{19}$.

Next we followed up the same cohort to describe the aetiologies, response to therapy, relapse rates and developmental outcomes. Follow up was at 3, 6, and 12 months. Twenty eight had minimum of three months of follow up while 17 completed 12 months of follow up. Median time to relapse was 3 months (0.518 months). There were relapses in $48 \%$ and the frequency of spasms during relapse was lower $(<50 \%)$ than at the onset. Development showed improvement in all but two children ${ }^{20}$.

Since our personal experience documented $65-70 \%$ response rates with ACTH or oral prednisolone, the time was right to find the answer to the question "Can oral prednisolone also be considered a first line form of therapy?" The answer to this could only be secured with a proper clinical trial. A few colleagues from the Faculty of Medicine got together to develop the background for a prospective, single blind, randomized clinical trial on low dose intramuscular $\mathrm{ACTH}$ versus moderate to high dose oral prednisolone therapy. Our multi-disciplinary team included me (JW) as a paediatric neurologist and Principal Investigator, an epidemiologist, a clinical pharmacologist cum paediatrician and a paediatrician with special training in development assessment. Ethical clearance was obtained from the Ethical Review Committees of the Faculty of Medicine, Colombo (EC/010/081) and the Lady Ridgeway Hospital, in October 2010. This trial was registered in the Sri Lanka Clinical Trials Registry (SLCTR/2010/010).

\section{Method}

Selection of the sample

Only newly diagnosed IS occurring in clusters were eligible for inclusion in the study. The patients were directly admitted or referred by other paediatricians. The diagnosis of IS was confirmed based on spasms directly observed by the Principal Investigator (JW) or in videos provided by parents. Of them, only those who had hypsarrhythmia recorded on the EEG were included. Age less than 2 months or more than 30 months or a diagnosis of tuberous sclerosis, previous treatment for West Syndrome (WS), those with contraindications for using hormonal therapies and parents incapable of monitoring the response to therapy were excluded.

Prior to treatment allocation, detailed baseline developmental assessments were performed, using the Bayley III Infant and Toddler Developmental Scales by one of the investigators, who has had special training on using the Bayley developmental scales.

\section{Method of randomization}

The minimum sample size required to achieve an expected effect size of $25 \%$ in the improvement of electrical and clinical response in WS was 45 in each treatment arm. Randomization was performed independently using computer-generated random numbers by one co-investigator who took no part in the recruitment or outcome assessment. Assignment to treatment arm was sequentially allocated and kept in sealed envelopes.

\section{Allocation and monitoring of treatment}

Treatment followed the guidelines of the UKISS protocol $^{15}$. Depot ACTH 40IU $(0.5 \mathrm{mg})$ intramuscularly every other day (EOD) for 14 days or daily oral prednisolone $40 \mathrm{mg}$ divided into 4 doses/day for 14 days was allocated and patients were reassessed on the $7^{\text {th }}$ day of treatment. The same generic preparations were used throughout the clinical trial [Oral prednisolone (SPMC) and Acton Prolangatum depot preparation of $\mathrm{ACTH}]$. 
A better outcome for infantile spasms: What is the evidence? Sri Lanka Journal of Child Health, 2015; 44(3): 129137

\section{Outcome assessment}

There were two short term primary outcomes assessed. They were: improvement in the severity of hypsarrhythmia (electrical response) and spasm cessation (clinical response). The secondary outcome was the development of adverse effects to treatment. The adverse effects were evaluated by one investigator on day 14, using a comprehensive list of adverse effects reported for prednisolone (PNL) and ACTH. Summary of all side effects experienced were reviewed by the clinical pharmacologist.

The electrical response was evaluated by assessing improvement of the severity of the hypsarrhythmia after 14 days of treatment. This was quantified using a hypsarrhythmia severity scale which had been described by Kramer et al depicted in Table $1^{21}$.

Table 1: Hypsarrhythmia scoring system

\begin{tabular}{|l|c|}
\hline \multicolumn{1}{|c|}{ Component } & Score \\
\hline A. Disorganization & \\
Good gradient \& synchrony (normal for age & 0 \\
Partially formed gradient with some synchrony & 1 \\
No gradient, some synchrony of background & 2 \\
Chaos, no synchrony, no gradient & 3 \\
\hline B. Diffuse delta activity & \\
$<50 \%$ & 0 \\
$\geq 50 \%$ but $<75 \%$ & 1 \\
$\geq 75 \%$ but $<100 \%$ & 2 \\
$100 \%$ & 3 \\
\hline C. Voltage & 0 \\
$<120 \mu \mathrm{V}$ & 1 \\
$120-200 \mu \mathrm{V}$ & 2 \\
$200-500 \mu \mathrm{V}$ & 3 \\
$>500 \mu \mathrm{V}$ & 0 \\
\hline D. Spikes and sharp waves & 1 \\
No spikes or sharp waves & 2 \\
Spikes at a frequency of $\leq 1 / 5 \mathrm{sec}$ & 3 \\
Spikes at a frequency of $1 / 5 \mathrm{sec}-1 / \mathrm{sec}$ & 1 \\
Spikes at a frequency of $\geq 1$ per sec & 1 \\
\hline E. Other items & 1 \\
Electrodecremental discharges & \\
Burst suppression in sleep & \\
Absence of normal sleep pattern & \\
Relative normalization in wakefulness & \\
\hline Adapted from Kramer et al $1997^{21}$ ) & \\
\hline
\end{tabular}

A single relatively uniform 10 -second segment that contained the most representative and severe hypsarrhythmic part of the tracing was chosen for scoring. The maximum total score was 16 for the most severe hypsarrhythmia and the minimum total score was 0 , which was for a normal EEG. Same evaluation was performed in the post-treatment EEG. The improvement was assessed as a reduction in the hypsarrhythmia score, on this pre (D 0) and post (D14) treatment EEG assessments. In order to assess the intra-observer reliability of hypsarrhythmia scores, randomly selected 40 EEGs (20 pre- and 20 posttreatment) were re-scored by the same investigator after two weeks. The level of agreement between the scores and repeat-scores was assessed using Spearman's correlation co-efficient.

Spasm control was evaluated using parent reported spasm diaries. Diary I was used to document spasm load from day 0-14. Diary II was used to document spasm control from day 15-42. Following definitions were used to describe spasm control: Spasm cessation was absence of any spasms (single or cluster) for more than 48 hours at review on day 14. Sustained spasm control was defined by the West Delphi group as "cessation of spasms within the first 14 days of therapy followed by sustained spasm control for the next 28 consecutive days". Spasm control on day 42 was absence of any spasm for 48 hours at the time of review. Spasm control at 3, 6 and 12 months were absence of any spasm for at least one preceding week at the time of these reviews.

\section{Results}

There were 128 eligible infants with confirmed WS reviewed by us during the study period and $115(90 \%)$ of them gave consent for participation. Only 110 underwent EEG evaluation and of them, 12 were excluded due to absence of hypsarrhythmia and one due to spontaneous resolution of spasms, leaving 97 who were randomised to receive Prednisolone (PNL) $[\mathrm{n}=48]$ and Corticotrophin (ACTH) $[\mathrm{n}=49]$. The majority (71\%) had an identified cause (symptomatic) for WS, $18 \%$ had no cause found after detailed history and examination, imaging (CT or MRI brain) and metabolic screening (cryptogenic) and 11\% did not complete the investigations due to a plethora of reasons. There was also no significant difference between the two groups in demographic characteristics, baseline seizure duration and severity $(p>0.05)$ as described in Table 2. No significant differences were also noted in those who were lost for follow up and those who continued with the study $(\mathrm{p}>0.05)$. 
A better outcome for infantile spasms: What is the evidence? Sri Lanka Journal of Child Health, 2015; 44(3): 129137

Table 2: Baseline characteristics of the children treated with prednisolone and ACTH (n=97)

\begin{tabular}{|c|c|c|c|}
\hline Baseline characteristic & Prednisolone $(n=48)$ & $\operatorname{ACTH~}(n=49)$ & P value** \\
\hline Age in months & $8.55(\mathrm{SD}=6.20)$ & $9.58(\mathrm{SD}=8.77)$ & 0.53 \\
\hline $\begin{array}{l}\text { Sex } \\
\text { Male } \\
\text { Female }\end{array}$ & $\begin{array}{l}25(52.1 \%) \\
23(47.9 \%)\end{array}$ & $\begin{array}{l}31(63.3) \\
18(36.7)\end{array}$ & 0.26 \\
\hline $\begin{array}{l}\text { Ethnicity } \\
\text { Sinhala } \\
\text { Tamil } \\
\text { Muslim }\end{array}$ & $\begin{array}{l}42(87.5 \%) \\
01(02.1 \%) \\
05(12.8 \%)\end{array}$ & $\begin{array}{l}42(85.7 \%) \\
02(04.1 \%) \\
05(10.2 \%)\end{array}$ & 0.85 \\
\hline $\begin{array}{l}\text { Gestation } \\
\text { Preterm } \\
\text { Term }\end{array}$ & $\begin{array}{l}06(10.4 \%) \\
41(87.2 \%)\end{array}$ & $\begin{array}{l}05(10.2 \%) \\
44(89.8 \%)\end{array}$ & 0.69 \\
\hline $\begin{array}{l}\text { Birth weight }(\mathrm{Kg}) \\
\text { Mean } \\
<2.5 \mathrm{Kg} \\
2.5 \mathrm{Kg} \text { or }>\end{array}$ & $\begin{array}{c}2.57(\mathrm{SD}=0.53) \\
17(37.0 \%) \\
29(63.0 \%)\end{array}$ & $\begin{array}{l}2.61(\mathrm{SD}=0.53) \\
16(33.3 \%) \\
32(66.7 \%)\end{array}$ & $\begin{array}{l}0.71 \\
0.71\end{array}$ \\
\hline $\begin{array}{l}\text { Age of onset of spasms } \\
<12 \text { months } \\
12 \text { months or }>\end{array}$ & $\begin{array}{l}45(95.7 \%) \\
02(04.3 \%)\end{array}$ & $\begin{array}{l}43(89.6 \%) \\
05(10.4 \%)\end{array}$ & 0.25 \\
\hline $\begin{array}{l}\text { Preceding/ concurrent seizures } \\
\text { Present } \\
\text { Absent }\end{array}$ & $\begin{array}{l}16(34.0 \%) \\
31(66.0 \%)\end{array}$ & $\begin{array}{l}15(30.6 \%) \\
34(69.4 \%)\end{array}$ & 0.72 \\
\hline $\begin{array}{l}\text { Previous treatment with anti-epileptic drugs } \\
\text { Yes } \\
\text { No }\end{array}$ & $\begin{array}{l}11(23.9 \%) \\
35(76.1 \%)\end{array}$ & $\begin{array}{l}13(27.1 \%) \\
35(72.9 \%)\end{array}$ & 0.72 \\
\hline
\end{tabular}

**p values obtained for assessing significant differences between the two treatment arms in relation to baseline characteristics (chisquare test used for categorical data; independent t test used for quantitative data)

Improvement in EEG

Of the 97 randomized infants, post treatment evaluation was completed by 46 on prednisolone and 47 on ACTH. Post-treatment EEGs on day 14 were performed by only 40 from each treatment arm. Improvement in the severity of hypsarrhythmia of the entire sample treated with either form of hormonal therapy was first considered. It showed an average pre- treatment score of $10.45(\mathrm{SD}=2.65)$, improving with treatment to an average post-treatment score of 3.45 $(\mathrm{SD}=2.67)$. The mean of (pre-post) treatment scores was $7.0(\mathrm{SD}=2.84)$, which was statistically significant (paired $\mathrm{t}=21.72 ; \mathrm{df}=77 ; \mathrm{p}<0.01$ ). All components of the severity scale showed significant improvement ${ }^{22}$ (Table 3).

Table 3: Improvement in the severity of hypsarrhythmia with hormonal therapies $(N=80)$

\begin{tabular}{|l|c|c|}
\hline $\begin{array}{c}\text { Components in the hypsarrhythmia } \\
\text { assessment tool }\end{array}$ & $\begin{array}{c}\text { Improvement in hypsarrhythmia scores* } \\
\text { Mean (SD) }\end{array}$ & Level of significance** \\
\hline Background organization & $1.74(1.11)$ & $<0.001$ \\
\hline Background slowing & $1.50(1.04)$ & $<0.001$ \\
\hline Amplitude & $1.12(0.82)$ & $<0.001$ \\
\hline Spike index & $1.19(0.98)$ & $<0.001$ \\
\hline Burst suppression & $0.42(0.54)$ & $<0.001$ \\
\hline Electro-decremental pattern & $0.12(0.49)$ & 0.02 \\
\hline Normalization in wakefulness & $0.43(0.62)$ & $<0.001$ \\
\hline Absence of sleep transients & $0.43(0.59)$ & $<0.001$ \\
\hline Overall score & $7.00(2.84)$ & $<0.001$ \\
\hline
\end{tabular}

*Improvement in the severity of hypsarrhythmia was assessed by the mean (pre-post) treatment scores

**p values obtained for assessing the significance of the mean of (pre-post) treatment scores, using paired t test

When the mean (pre-post) treatment scores were compared between the two groups, the PNL group showed a significantly greater improvement in severity than the ACTH group (7.95 \pm 2.76 vs $6.00 \pm$ $2.61 ; \mathrm{p}<0.01)$ (Table 4). When the mean (pre-post) treatment score of each individual component was assessed, all components improved better with PNL than with ACTH but were significant only in the spike index (Table 4). 
A better outcome for infantile spasms: What is the evidence? Sri Lanka Journal of Child Health, 2015; 44(3): 129137

Table 4: Comparison of the improvement of hypsarrhythmia severity between PNL group and ACTH group

\begin{tabular}{|l|c|c|c|}
\hline \multirow{2}{*}{$\begin{array}{c}\text { Components in the } \\
\text { hypsarrhythmia scores }\end{array}$} & Improvement in the hypsarrhythmia severity* & $\begin{array}{c}\text { Level of significance** } \\
\text { 'p' value }\end{array}$ \\
\cline { 2 - 4 } & $\begin{array}{c}\text { PNL Group } \\
\text { Mean (SD) }\end{array}$ & $\begin{array}{c}\text { ACTH Group } \\
\text { Mean (SD) }\end{array}$ & 0.2 \\
\hline Organization & $1.90(0.90)$ & $1.57(1.28)$ & 0.51 \\
\hline Background slowing & $1.57(1.08)$ & $1.42(1.00)$ & 0.05 \\
\hline Amplitude & $1.30(0.79)$ & $0.94(0.83)$ & 0.004 \\
\hline Spike index & $1.50(0.90)$ & $0.86(0.96)$ & 0.09 \\
\hline Burst suppression & $0.52(0.59)$ & $0.31(0.47)$ & 0.95 \\
\hline Electro-decremental pattern & $0.12(2.76)$ & $0.13(0.57)$ & 0.48 \\
\hline Normalization in wakefulness & $0.48(0.67)$ & $0.38(0.65)$ & 0.33 \\
\hline Absence of sleep transients & $0.50(0.55)$ & $0.36(0.63)$ & 0.002 \\
\hline Overall score & $7.95(2.76)$ & $6.00(2.61)$ & \\
\hline
\end{tabular}

*Improvement in the hypsarrhythmia severity was assessed by the mean of (pre-post) treatment scores

**p values obtained for assessing the significant difference of the mean (pre-post) treatment scores between the two treatment groups, using paired t test

Owing to multiple comparisons, the level of significance was adjusted to $p<0.00625$ by Bonferroni correction: $\alpha$ adjusted $=\alpha / c$ (where $\alpha$ is the overall experiment wise alpha (0.05); $c$ is the number of comparisons made (9)

Spasm control

Clinical response of spasm cessation at day 14 of treatment was completed by 93 infants (46 PNL, 47 ACTH). Twenty eight (61\%) were spasm free on day 14 with PNL compared to 18 (38\%) on ACTH $(\mathrm{p}=0.03)$. Average number of days for spasm cessation was 3.85 (SD 2.4) for PNL and 8.47 days (SD 3.83) for ACTH $(\mathrm{p}<0.01)$. When we looked at the percentage where no change occurred with the hormonal therapy, there were 4 infants $(9.8 \%)$ on prednisolone compared to $16(39 \%)$ on $\mathrm{ACTH}$ without any clinical response $(\mathrm{p}=0.002)$.

\section{Secondary outcome - tolerability}

Both forms of therapy were well tolerated. Weight gain, increased appetite, frequent crying spells and abdominal distension were experienced more frequently in those treated with PNL (Table 5). However, none were significant and did not result in any withdrawals. Withdrawal from the protocol was required only for one child in PNL group, due to hypertension. This settled within 24 hours of observation in the ward with a single dose of sublingual nifedipine. During the trial period of five weeks which included the treatment regime and taper off periods, no deaths were observed.

Table 5: Comparison of side effects experienced with prednisolone and ACTH (N=80)

\begin{tabular}{|l|c|c|c|}
\hline \multicolumn{1}{|c|}{ Side effect } & $\begin{array}{c}\text { Prednisolone } \\
\text { Number (\%) }\end{array}$ & $\begin{array}{c}\text { ACTH } \\
\text { Number (\%) }\end{array}$ & $\begin{array}{c}\text { Level of significance* } \\
\text { 'p' value }\end{array}$ \\
\hline Increased appetite & $25(78.5)$ & $15(42.9)$ & 0.006 \\
\hline Weight gain & $17(51.5)$ & $10(28.6)$ & 0.05 \\
\hline Frequent crying spells & $15(45.5)$ & $08(22.9)$ & 0.04 \\
\hline Drowsiness & $03(09.1)$ & $06(17.1)$ & 0.32 \\
\hline Cushingoid features & $08(24.2)$ & $05(14.3)$ & 0.29 \\
\hline Insomnolence & $03(09.1)$ & $01(02.9)$ & 0.27 \\
\hline Lethargy & $02(06.1)$ & $01(02.9)$ & 0.52 \\
\hline Reduction in social behaviour & $02(06.1)$ & $01(02.9)$ & 0.52 \\
\hline Abdominal distension & $07(21.2)$ & $00(0.0)$ & 0.004 \\
\hline Hypertension & $01(03.0)$ & $01(02.9)$ & 0.99 \\
\hline Increased susceptibility to infection & $00(0.0)$ & $01(02.9)$ & 0.32 \\
\hline Irritability & $08(24.2)$ & $02(05.7)$ & 0.03 \\
\hline Nausea & $01(03.0)$ & $00(0.0)$ & 0.29 \\
\hline Vomiting & $01(03.0)$ & $00(0.0)$ & 0.29 \\
\hline Diarrhoea & $02(06.1)$ & $01(02.9)$ & 0.52 \\
\hline Dyspepsia & $01(03.0)$ & $01(02.9)$ & 0.96 \\
\hline Electrolyte imbalances & $02(06.1)$ & $00(0.0)$ & 0.32 \\
\hline
\end{tabular}

*Owing to multiple comparisons, the level of significance was adjusted to $p<0.00294$ by Bonferroni correction:

$\alpha_{a d j u s t e d}=\alpha / c$ (where $\alpha$ is the overall experiment wise alpha (0.05); $c$ is the number of comparisons made (17). 
Ladies and Gentlemen, the findings in our trial with regard to immediate spasms control as well as improvement of hypsarrhythmia were significantly better with oral prednisolone. We are the first group to document this therapeutic supremacy worldwide.

Next we evaluated the effect on sustained spasm control. Out of the 93 evaluated on day 14 , twenty nine infants remained spasm free for more than 28 consecutive days. They included 19/46 treated with prednisolone versus 10/47 given intramuscular ACTH. This confirmed that oral prednisolone resulted in better sustained spasms control $(\mathrm{p}=0.02)$. Sustained spasm control was considered a better indicator of immediate spasm control by the West Delphi group ${ }^{23}$.

Long term spasm control was assessed at two different time points: a) short term follow up (6 weeks and 3 and 6 months) and b) long term follow up (12 months). In the short term follow up, 40 of prednisolone and 37 of ACTH completed the 6 week evaluation. Spasm cessation was seen in $32(69 \%)$ given PNL against 17 $(36 \%)$ for ACTH at 6 weeks $(\mathrm{p}=0.002)$. At 3 months evaluation, $29(63 \%)$ out of the 46 given PNL versus $19(40 \%)$ out of 47 given ACTH remained spasm free $(\mathrm{p}=0.003)$. This finding confirmed that during short term follow up, spasm freedom was significantly higher if treated with prednisolone.

Likelihood of long term spasm freedom was evaluated at two further time points, 6 and 12 months. Six month follow up was completed by 73 out of 90 by the time of submission of this manuscript for the oration. Spasm control was seen in $77 \%$ treated with PNL as against $53 \%$ being treated with ACTH $(p=0.05)$. However, the 46 who completed 12 months review at time of submission showed no significant difference between the outcomes for the two treatment arms.

During this follow up period of up to one year, 5 deaths have occurred. None occurred during the treatment phase or the taper-off period of three weeks. The causes of death are known in 4 and these were aspiration pneumonia, hepatoblastoma, acute renal failure due to sepsis and community acquired pneumonia.

\section{Hormonal therapies and developmental outcome}

As outlined in several meta-analyses, although the short term control of spasms is better with hormonal therapies, we are still unable to show whether it results in better developmental outcomes in the long term. The assessment of the Vinyl Adoptive Behavioural Scores at 4 years post treatment via a telephone interview in the UKISS study showed that in those with a cryptogenic aetiology, the developmental outcome was better if they were treated with hormonal therapies.

A highlight of our study is the detailed assessment of the developmental outcomes. This was done using Bayley III infant and toddler developmental scales, which is the gold standard for developmental assessment in research. The Bayley scales evaluate the domains of cognition, language and motor components. Raw scores were calculated and converted to scaled and composite values. All assessments were performed by a single trained and qualified researcher who remained blinded to treatment details. These developmental assessments were performed at diagnosis (baseline) and subsequently at 1 year and 2 years post treatment. Their developmental attainments at the baseline were analysed according to the age of presentation, the duration of spasms prior to the presentation and the aetiology of spasms.

\section{Results}

Baseline developmental assessments showed the composite scores for cognitive $58.4(+/-8.046)$ language $56.6(+/-12.752)$ and motor $50.74(+/-$ 8.378) functions and all these mean scores were below average. The much anticipated finding would be the developmental outcomes in the two groups of patients. We have looked at the development at two years post treatment. Currently we have evaluated 47 at 1 year and 29 at 2 years. In the 47 who completed one year evaluations, all had a symptomatic aetiology. Mean age of onset of spasms was $6.57(\mathrm{SD}=4.87)$ months. The mean age at presentation was $9.25(\mathrm{SD}=6.07)$ months. The mean gap between onset of spasms and the presentation was 71.15 days $(\mathrm{SD}=75.47)$. The mean duration of review from the commencement of treatment was 12.06 months $(\mathrm{SD}=3.51)$. All children had mean Bayley scaled scores below average (less than 4) at presentation and at one year. The mean comparisons of the scaled scores showed a deterioration of scores in all domains at one year. There was no significant relationship with any risk factors for adverse developmental outcome such as longer duration of spasms before treatment and poor spasm control after initial 14 days of therapy.

\section{The Future}

We believe that we have achieved a milestone. We have shown definitive evidence of efficacy and safety of prednisolone in the treatment of epileptic spasms. This has been taken up by the world and is now in the world literature. This evidence, we deduce, will benefit children suffering from epileptic spasms and their doctors, particularly in developing countries. The results have been welcomed even by those from the 
A better outcome for infantile spasms: What is the evidence? Sri Lanka Journal of Child Health, 2015; 44(3): 129137

West. Do we stop here? I think NOT. How can we target a better overall outcome? A better outcome would be a possible prevention of development of spasms and reversal of EEG changes. This is the hypothesis of our next project titled "Interventional study on the role of prednisolone as a preventer of development of West Syndrome".

This new research hypothesis is based on evidence of evolutionary stages of hypsarrhythmia prior to the development of spasms (Pre-spasm stage) ${ }^{3,24,25}$. Utilising this EEG change as a biomarker of risk of spasm development, we hypothesise that treatment with oral prednisolone early would potentiate "prevention" of WS. This has never been tested anywhere prospectively. We are in the planning stage of this intervention in a cohort of infants with strong biomarkers for development of infantile spasms. This I believe is indeed the future direction of research on infantile spasms.

\section{Acknowledgements}

I wish to thank the Sri Lanka Medical Association for part funding this clinical trial, my coinvestigators and the many collaborators who contributed to the success of this project, the staff of the University Paediatric unit at the Lady Ridgeway Hospital for their support, the patients and parents for their participation and to Dr. B J C Perera for helping me in the preparation of the manuscript.

\section{References}

1. William W. On a peculiar form of infantile convulsions. Lancet 1841; 35:724-5. http://dx.doi.org/10.1016/S01406736(00)40 184-4

2. Wanigasinghe J. Late onset epileptic spasms due to late onset cerebral insult. Annual Scientific Sessions of Association of Sri Lankan Neurologists. Colombo, 2013. p. 49. PMid: 23549725

3. Philippi H, Wohlrab G, Bettendorf U, Borusiak P, Kluger G, Strobl K, et al. Electroencephalographic evolution of hypsarrhythmia: toward an early treatment option. Epilepsia 2008;49:1859-64. http://dx.doi.org/10.1111/j.15281167.2008.0 1715.x

PMid: 18631366
4. Hancock EC, Osborne JP, Edwards SW. Treatment of infantile spasms. The Cochrane Database of Systematic Reviews 2013;6:CD001770. http://dx.doi.org/10.1002/14651858.cd00177 0.pub3

5. Go CY, Mackay MT, Weiss SK, Stephens D, Adams-Webber T, et al. Evidence-based guideline update: medical treatment of infantile spasms. Report of the Guideline Development Subcommittee of the American Academy of Neurology and the Practice Committee of the Child Neurology Society.Neurology 2012, 78:1974-80. http://dx.doi.org/10.1212/WNL.0b013e3182 $59 \mathrm{e} 2 \mathrm{cf}$

PMid: 22689735 PMCid: PMC3369510

6. Watanabe K. Medical treatment of West syndrome in Japan. Journal of Child Neurology 1995;10:143-7. http://dx.doi.org/10.1177/088307389501000 217

PMid: 7782606

7. Sorel L, Dusaucy-Bauloye A: [Findings in 21 cases of Gibbs' hypsarrhythmia; spectacular effectiveness of ACTH]. Acta Neurologica et Psychiatrica Belgica 1958; 58:130-41. PMid: 13532578

8. Kossoff EH, Hartman AL, Rubenstein JE, Vining EP. High-dose oral prednisolone for infantile spasms: an effective and less expensive alternative to ACTH. Epilepsy \& Behavior : E\&B 2009;14:674-6.

http://dx.doi.org/10.1016/j.yebeh.2009.01.023 PMid: 19435579

9. Wheless JW, Clarke DF, Arzimanoglou A, Carpenter D: Treatment of paediatric epilepsy: European expert opinion, 2007. Epileptic disorders2007;9:353-412.

PMid: 18077226

10. Chiron C, Dumas C, Jambaque I, Mumford J, Dulac O: Randomized trial comparing vigabatrin and hydrocortisone in infantile spasms due to tuberous sclerosis. Epilepsy Research 1997;26:389-95. http://dx.doi.org/10.1016/S09201211(96)01 006-6 
A better outcome for infantile spasms: What is the evidence? Sri Lanka Journal of Child Health, 2015; 44(3): 129137

11. Appleton RE, Peters AC, Mumford JP, Shaw DE: Randomised, placebo-controlled study of vigabatrin as first-line treatment of infantile spasms. Epilepsia 1999;40:1627-33. http://dx.doi.org/10.1111/j.15281157.1999.t b02049.x

12. Arya R, Shinnar S, Glauser TA: Corticosteroids for the treatment of infantile spasms: a systematic review. Journal of Child Neurology 2012; 27:1284-8. http://dx.doi.org/10.1177/0883073812453203

PMid: 22859699

13. Baram TZ, Mitchell WG, Tournay A, Snead OC, Hanson RA, Horton EJ: High-dose corticotropin (ACTH) versus prednisone for infantile spasms: a prospective, randomized, blinded study. Pediatrics 1996, 97:375-9. PMid: 8604274 PMCid: PMC3100715

14. Hrachovy RA, Frost JD, Jr., Kellaway P, Zion TE: Double-blind study of ACTH vs prednisone therapy in infantile spasms. The Journal of Pediatrics 1983;103:641-5. http://dx.doi.org/10.1016/S00223476(83)80 606-4

15. Lux AL, Edwards SW, Hancock E, Johnson AL, Kennedy CR, Newton RW, O'Callaghan FJ, Verity CM, Osborne JP: The United Kingdom Infantile Spasms Study comparing vigabatrin with prednisolone or tetracosactide at 14 days: a multicentre, randomised controlled trial. Lancet 2004;364:1773-8. http://dx.doi.org/10.1016/S01406736(04)17 400-X

16. Lux AL, Edwards SW, Hancock E, Johnson AL, Kennedy CR, Newton RW, O'Callaghan FJ, Verity CM, Osborne JP, United Kingdom Infantile Spasms S: The United Kingdom Infantile Spasms Study (UKISS) comparing hormone treatment with vigabatrin on developmental and epilepsy outcomes to age 14 months: a multicentre randomised trial. Lancet Neurology 2005;4:712-7. http://dx.doi.org/10.1016/S14744422(05)70 199-X

17. Kudalugoda Arachchi J SMP, Lamabadusuriya S P L. ACTH therapy for infantile spasms and syndromic epilepsies.
Proceedings of the Sri Lanka College of Paediatricians 9th Annual Scientific Congress, 2005. p. 34.

18. Wanigasinghe J. Experience with the UKISS protocol for treating infantile spasms in a South Asian country. International Conference of Paediatric Neurology and Epilepsy. Edited by Singhi P. Chandigar, India: Praveen Sharma, 2009. pp. 147-8.

19. Wanigasinghe J. Treating infantile spasms using the UKISS protocol -Experience from a developing country. The 26th International Paediatric Association Congress of Paediatrics. Johannesburg, South Africa, 2010. p. 1031.

20. Wanigasinghe J, Jayasena Y A A, Dilanka S. Infantile spasm control and developemntal progression following short course therapy with steroids/ vigabatrin. 8th Asian \& Oceanian Epilepsy Congress. Melbourne, Australia, 2010. p. 173.

21. Kramer U, Sue WC, Mikati MA. Hypsarrhythmia: frequency of variant patterns and correlation with etiology and outcome. Neurology 1997;48:197-203. http://dx.doi.org/10.1212/WNL.48.1.197 PMid: 9008518

22. Wanigasinghe J, Arambepola C, Sri Ranganathan S, Sumanasena S, Muhandiram EC. The efficacy of moderate-to-high dose oral prednisolone versus low-to-moderate dose intramuscular corticotropin for improvement of hypsarrhythmia in West syndrome: a randomized, single-blind, parallel clinical trial. Pediatric Neurology 2014;51:24-30.

http://dx.doi.org/10.1016/j.pediatrneurol.201 4.03.014

PMid: 24938136

23. Lux AL, Osborne JP. A proposal for case definitions and outcome measures in studies of infantile spasms and West syndrome: consensus statement of the West Delphi group. Epilepsia 2004;45:1416-28. http://dx.doi.org/10.1111/j.00139580.2004.0 2404.x

PMid: 15509243 
A better outcome for infantile spasms: What is the evidence? Sri Lanka Journal of Child Health, 2015; 44(3): 129137

24. Kato T, Okumura A, Hayakawa F, Tsuji T, Hayashi S, Kubota T, Fukasawa T, Suzuki M, Maruyama K, Oshiro M, Hattori T, Kidokoro $\mathrm{H}$, Natsume J, Hayakawa M, Watanabe K: Prolonged EEG depression in term and nearterm infants with hypoxic ischemic encephalopathy and later development of West syndrome. Epilepsia 2010;51:2392-6. http://dx.doi.org/10.1111/j.15281167.2010.0 2727.x

PMid: 20887363

25. Guggenheim MA, Frost JD, Jr., Hrachovy RA: Time interval from a brain insult to the onset of infantile spasms. Pediatric Neurology 2008;38:34-7.

http://dx.doi.org/10.1016/j.pediatrneurol.2007.08. 005

PMid: 18054690 